\title{
A EQUIDADE INTERGERACIONAL: UMA ANÁLISE DOS DIREITOS DA NATUREZA EM CONSTITUIÇÕES LATINO-AMERICANAS
}

\section{Débora Gomes Galvão* Juliana Buck Gianini**}

RESUMO: A pesquisa aborda a teoria da equidade intergeracional, com análise dos direitos da natureza em Constituições Latino-Americanas. Tal teoria preconiza que as gerações humanas, conservando e repassando às seguintes nas mesmas ou melhores condições em que receberam. Dividiu-se em: dimensão temporal no Direito Internacional, com uma breve análise de uma nova racionalidade entre a sociedade humana e a natureza; Teoria da Equidade Intergeracional e o Desenvolvimento Sustentável, e os desafios para um novo constitucionalismo com inserção da natureza das Constituições mencionadas. Constatou-se que a tendência latino-americana de romper com paradigmas antropocêntricos ocidentais já é conhecida e reputada no Brasil.

Palavras-chave: Equidade Intergeracional. Desenvolvimento Sustentável. Direitos da Natureza. Sujeitos de Direito. Constituições Latino-americanas.

\section{THE INTERGERATIONAL EQUITY: AN ANALYSIS OF NATURE'S RIGHTS IN LATIN AMERICAN CONSTITUTIONS}

ABSTRACT: This paper addresses the theory of intergenerational equity, with analysis of the rights of nature in Latin American Constitutions. Such theory advocates that the human generations, preserving and passing on the following in the same or better conditions in which they received. It was divided into: a temporal dimension in International Law, with a brief analysis of a new rationality between human society and nature; Theory of Intergenerational Equity and Sustainable Development, and the challenges to a new constitutionalism with insertion of the nature of the mentioned Constitutions. It was found that the Latin American tendency to break with Western anthropocentric paradigms is already known and reputed in Brazil.

Keywords: Intergenerational Equity. Sustainable development. Rights of Nature. Subjects of Law. Latin American Constitutions.

\footnotetext{
* Doutoranda em Direito Ambiental Internacional pela Universidade Católica de Santos (UNISANTOS). Mestre em Ciência Política, pela Universidade Federal do Piauí. Bolsista Capes Prosup, tem experiência na área de Direito e de Ciência Política, atualmente, trabalha com consultoria e desenvolve pesquisa em Direito Ambiental Internacional, atuando principalmente nos seguintes temas: Governança Global, Desenvolvimento Sustentável, Agenda 2030, Paradiplomacia Ambiental e Implementação dos Objetivos de Desenvolvimento Sustentável no Estado do Piauí. Email: deboragalvao@unisantos.br.

${ }^{* *}$ Doutoranda em Direito Ambiental Internacional pela Universidade Católica de Santos (UNISANTOS). Mestre em Direito Ambiental pela Universidade Católica de Santos (UNISANTOS) . Delegada de Polícia, desenvolvendo pesquisa com ênfase no meio ambiente. Email: julianabuck@ hotmail.com.
}

CONPEDI LAW REVIEW | QUITO - EQUADOR | v. 4 | n. 2 | p. 1 - 20 | JUL - DEZ | 2018 


\section{INTRODUÇÃO}

Doutrinadores de distintos países passaram a abordar sobre o tema da equidade intergeracional no campo do Direito Ambiental Internacional ${ }^{1}$ (LIMA 2008; LEITE e AYALA, 2001; WARREN, 2010).

Nesta perspectiva, é válido destacar que, o conceito de equidade intergeracional surgiu nos anos de 1980 e está intrinsecamente relacionado com a ansiedade desencadeada pelas mudanças globais que caracterizaram a segunda metade do Século XX, visto que o poder da humanidade de mudar e transformar as características físicas da Terra alcançou um nível que dificilmente poderia ser imaginado há um Século, e, ao mesmo tempo, a população mundial aumentou numa velocidade sem precedentes, chegando mesmo a dobrar em algumas décadas (KIS, 2004).

Weiss, professora da Faculdade de Direito da Universidade de Georgetown e também consultora do "American Journal of International Law", precursora da teoria da equidade intergeracional, traça um arcabouço jurídico a partir dos acordos internacionais firmados, tendo como teoria de base o igualitarismo de John Rawls ${ }^{2}$, bem como a "noção de desenvolvimento sustentável" (WEISS, 1993, p. 15).

A preocupação com a justiça para as gerações futuras em relação ao meio ambiente natural surgiu como uma grande preocupação nas reuniões preparatórias para a Conferência de Estocolmo de 1972 sobre o Meio Humano.

O preâmbulo da Declaração de Estocolmo sobre o meio ambiente humano refere-se expressamente ao objetivo de proteger o bem-estar das gerações futuras, "...defender e melhorar o meio ambiente para as gerações atuais e futuras tornou-se um objetivo imperativo para a humanidade, objetivo para ser perseguido e em harmonia com os objetivos

\footnotetext{
${ }^{1}$ A preocupação com o bem-estar das futuras gerações, a despeito de sua presença massiva em uma série de documentos internacionais e na literatura ambiental especializada em tempos recentes, não é um conceito novo. Já se fazia presente nos escritos de filósofos como Cícero, Kant, Bentham, Locke, Marx e outros (CARVALHO, 2006).

${ }^{2}$ Edith Brown Weiss traça um desenvolvimento jurídico da equidade intergeracional, a partir dos acordos internacionais firmados e tendo como teoria de base o igualitarismo de Jonh Rawls, e também na noção de desenvolvimento sustentável. O objetivo de Rawls é elaborar uma teoria da justiça com a equidade que se apresente como alternativa ao utilitarismo em suas diversas versões, procurando formular uma concepção de justiça com equidade, colocando-a como base articuladora da justiça, tendo como objetivo central superar a debilidade teórica da filosofia moral predominante no mundo anglo-saxão, combatendo principalmente a tese utilitarista que prioriza o bem em relação ao justo (RAWLS, 2006, p.25).
}

CONPEDI LAW REVIEW | QUITO - EQUADOR | v. 4 | n. 2 | p. 1 - 20 | JUL - DEZ | 2018 


\section{A EQUIDADE INTERGERACIONAL: UMA ANÁLISE DOS DIREITOS DA NATUREZA EM CONSTITUIÇÕES LATINO-AMERICANAS}

estabelecidos e fundamentais da paz e do desenvolvimento econômico e social mundial [...]"(ONU, 2018, s.p.).

Já em 1992, na Conferência das Nações Unidas sobre o Meio Ambiente e o Desenvolvimento, a intenção era introduzir a ideia do desenvolvimento sustentável, como um modelo de crescimento econômico menos consumista e mais adequado ao equilíbrio ambiental, bem como a implementação deste compromisso com as gerações futuras.

A mudança ambiental global afeta nossa capacidade de alcançar o desenvolvimento sustentável, por sua vez, o desenvolvimento econômico causa mudanças ambientais globais. As implicações da mudança ambiental global são inerentemente de longo prazo e exigem que abordemos problemas de equidade que ocupem as gerações futuras.

Desenvolvemos instrumentos econômicos para tentar satisfazer eficientemente as necessidades da geração atual, mas não são necessariamente adequados para abordar questões de equidade com as gerações futuras.

Todos têm direito ao meio ambiente ecologicamente equilibrado, nesse contexto -recentes Constituições da América Latina, como a do Equador de 2008 e a da Bolívia de 2009, trazem uma redefinição de sociedade sustentável, em detrimento do crescimento econômico descomedido, trazendo propostas inovadoras para superar ameaças globais à biodivesidade e de conscientizar a construção de uma sociedade que seja parte da natureza e que com ela conviva harmonicamente.

Assim, a proposta da presente pesquisa, é destacar a teoria da Equidade Integeracional, com uma análise da natureza nas constituições Latino-Americanas, e os valores advindos desse novo Constitucionalismo, por meio de um avanço para uma dimensão ecológica, fundados no de direitos da natureza.

O que resulta em um rearranjo na visão mundial, com a prática de vida menos consumista e com valores intergeracionais para alcançar uma comunidade unida à natureza, em prol de um desenvolvimento sustentável.

Para tanto, questiona-se: pode um rio pleitear direitos antipoluição na justiça? É uma tendência que pode alterar o estatuto jurídico da natureza no Brasil. Constitucionalismo já adotado em países da América Latina, como será abordado, que já trazem uma ampliação da proteção ambiental aproximando por exemplo, direitos de rios e animais aos assegurados aos humanos.

A metodologia empregada para o estudo foi exploratória de caráter bibliográfico com análise da doutrina, jurisprudência, normas nacionais e estrangeiras e projetos normativos 
afetos ao tema, principalmente com recortes constitucionais dos países latinos americanos, como Brasil, Equador e Bolívia.

Dessa forma, dividiu-se em três partes, a primeira tratando da dimensão temporal no Direito Internacional, com uma breve análise de uma nova racionalidade entre a sociedade humana e a natureza.

A segunda e a terceira, respectivamente, discorrendo sobre a "Teoria da Equidade Intergeracional" e o "Desenvolvimento Sustentável", para uma harmonia da comunidade humana com a natureza e os desafios para um novo constitucionalismo com inserção da natureza nas Constituições Latino-americanas.

Por fim, consegue-se inferir que a tendência latino-americana (à exemplo do Equador e da Bolívia) de romper com paradigmas antropocêntricos ocidentais, já é conhecido e reputado no Brasil.

\section{A DIMENSÃO TEMPORAL NO DIREITO INTERNACIONAL: BREVE ANÁLISE DE UMA NOVA RACIONALIDADE ENTRE A SOCIEDADE HUMANA E A NATUREZA}

O reconhecimento da solidariedade como elemento de sustentação de uma nova ética constitui o marco teórico do princípio da equidade intergeracional, particularmente nos debates sobre a responsabilidade comum, porém diferenciada, em enfrentar a problemática das mudanças ambientais.

Nesta seara, o direito internacional até agora abordou questões intertemporais principalmente no contexto da relação entre o presente e o passado. Em 1975, por exemplo, o Institut de Droit International adotou uma Resolução que autorizava uso do direito intertemporal. A atitude do Instituto incentivou os Estados a desenvolverem um acordo entre eles sobre como lidar com problemas intertemporais, que poderiam surgir na negociação de tratados e outros acordos internacionais.

No entanto, não se estendeu além da formulação clássica para incluir outras questões intertemporais relacionadas, como o desenvolvimento do direito internacional por declarações e resoluções internacionais da Assembléia Geral das Nações Unidas. 


\section{A EQUIDADE INTERGERACIONAL: UMA ANÁLISE DOS DIREITOS DA NATUREZA EM CONSTITUIÇÕES LATINO-AMERICANAS}

Segundo Brown (1992), embora a maioria das disputas que embasam a teoria intertemporânea tenham envolvido reivindicações territoriais ${ }^{3}$, a doutrina é aplicável mais amplamente a outras questões do direito internacional consuetudinário e aos Tratados Internacionais.

Existem várias questões intertemporais levantadas pelos tratados: a interpretação adequada de um tratado ao longo do tempo, a continuidade da validade de um tratado diante de mudanças de circunstâncias e a aplicação retroativa.

A Convenção de Viena sobre o Direito dos Tratados contém disposições específicas que abordam essas questões, embora a doutrina do direito intertemporal não seja explicitamente mencionada. ${ }^{4}$

As doutrinas do direito internacional consuetudinário, como pacta sunt servanda e rebus sic stantibus, respondem à questão intertemporânea da continuação validade dos tratados $^{5}$. Outrossim, problemas intertemporais também surgem no contexto de regras processuais estabelecidas pelos tribunais internacionais.

Trindade (1983) afirma, por conseguinte, que essas questões são importantes nos casos de direitos humanos, particularmente aqueles em que a Convenção Europeia dos Direitos Humanos prevê que a Comissão Europeia de Direitos Humanos possa resolver a questão do esgotamente dos remédios locais apenas no prazo de seis meses a contar da data da decisão final. Embora os prazos para essas questões processuais intertemporais sejam relativamente breves, as questões tratadadas, demonstram que já estamos abordando questões intertemporais rotineiramente no direito internacional ao relacionar presente com o passado. Assim, há um elemento temporal em muitos aspectos do direito internacional público e das tradições jurídicas nacionais.

\footnotetext{
${ }^{3}$ Na Opinião Consultiva de Namíbia de 1971, quando o Tribunal Mundial examinou se a presença da África do Sul na Namíbia em virtude do mandato da Liga das Nações de 1919 se continuava a ser válida, concluiu que o significado de "confiança sagrada" evoluiu para "autodeterminação e independência do povo", não sustentando a reivindicação da África do Sul. Embora o Tribunal não tenha se referido ao direito intertemporal, MacWhinney classificou-o corretamente como tendo "abraçado-o".

${ }^{4}$ Ver, por exemplo, art. 28 (não retroatividade dos tratados), art. 31 (regra geral de interpretação), art. 32 (meios complementares de interpretação) e art. 62 (alteração fundamental das circunstâncias), Convenção de Viena sobre o Direito dos Tratados, 23 de maio de 1969.

${ }^{5}$ A máxima pacta sunt servanda ("tratados devem ser observados") foi temperada pelo princípio da rebus sic stantibus ("enquanto as coisas permanecem como estão agora"), que sustenta que as obrigações dos tratados são encerradas no caso de uma mudança fundamental nas circunstâncias existentes no momento em que o tratado foi concluído, desde que o consentimento das partes fosse baseado na existência daquelas circunstâncias. No que se refere ao Artigo de n. 62 da Convenção de Viena sobre o Direito dos Tratados, os escritores Sinclair em "A Convenção de Viena sobre o Direito dos Tratados" (Manchester, 1984, p.192-194) e S. Rosenne, em "O Direito dos Tratados: Um Guia para a História Legislativa da Convenção de Viena” (Oceana, 1970, p.324-327), acreditam na codificação da prática atual sobre a mudança de circunstâncias nos Tratados.
}

CONPEDI LAW REVIEW | QUITO - EQUADOR | v. 4 | n. 2 | p. 1 - 20 | JUL - DEZ | 2018 
Cabe ressaltar, também, que desde a Segunda Guerra Mundial, os Estados expressaram preocupação em documentos legais internacionais para o bem-estar das gerações futuras. Um número crescente de acordos internacionais, declarações, cartas e resoluções da Assembléia Geral das Nações Unidas refletem tal preocupação e estabelecem princípios ou obrigações destinados a proteger e melhorar o bem-estar das gerações presentes e futuras.

A preocupação com a justiça para as gerações futuras em relação ao meio ambiente natural surgiu como uma grande preocupação nas reuniões preparatórias para a Conferência de Estocolmo de 1972 sobre o Meio Humano.

O preâmbulo da Declaração de Estocolmo sobre o meio ambiente humano refere-se expressamente ao objetivo de proteger o bem-estar das gerações futuras, defender e melhorar “o meio ambiente para as gerações atuais e futuras tornou-se um objetivo imperativo para a humanidade - objetivo para ser perseguido e em harmonia com os objetivos stabelecidos e fundamentais da paz e do desenvolvimento econômico e social mundial" (UNITED NATIONS,1972, s.p.).

O primeiro princípio da Declaração prevê que “[...] o homem assume uma solene responsabilidade de proteger e melhorar a ambiente para as gerações presentes e futuras ", enquanto o segundo declara que os" recursos naturais da terra, incluindo o ar, a água, a terra, a flora e a faunadevem ser salvaguardados para o benefício das gerações presentes e futuras através de um planejamento cuidadoso e gestão" (UNITED NATIONS,1972, s.p.).

Segundo Brown (1992), a Conferência de Estocolmo que levou diretamente à criação do Programa das Nações Unidas para o Meio Ambiente (PNUMA), com a preocupação explícita com as gerações futuras e a melhoria do meio ambiente, contribuiu para o processo de desenvolvimento do direito internacional nesta área.

A teoria da equidade intergeracional encontra forte respaldo na ciência jurídica, sendo implementada através de instrumentos legais internacionais e nacionais, positivando a proteção dos recursos ambientais para com as futuras gerações.

Importante destacar, ainda, que o estudo desta teoria não está restrito a proposta formulada por Edith Brow Weiss, podendo ser estudado sob outros enfoques (BOLSON, 2012, p. 225):

Há distintas teorias sobre justiça intergeracional, a de John Rawls é uma delas, ao lado dela há a utilitarista, a do libertarismo (cláusula lockeana), a 


\section{A EQUIDADE INTERGERACIONAL: UMA ANÁLISE DOS DIREITOS DA NATUREZA EM CONSTITUIÇÕES LATINO-AMERICANAS}

da reciprocidade indireta (de Brian arry), a das vantagens mútuas, a do suficienticismo (de Brundtland) e a do igualitarismo revisitado. Em recente conferência internacional - Ways to Legally Implement Intergenerational Justice - realizada em Lisboa, em 2010, discutiu-se, também no plano ambiental, os caminhos para a implementação de uma justiça entre gerações.

$\mathrm{O}$ conceito de proteger $\mathrm{o}$ ambiente natural para as gerações futuras foi explicitamente incorporado na linguagem de três tratados negociados mais ou menos contemporaneamente com a Declaração de Estocolmo: a Convenção de 1972 sobre o dumping dos oceanos de Londres, a Convenção de 1973 sobre comércio internacional de espécies ameaçadas e a Convenção de 1972 sobre à Proteção do Patrimônio Mundial Cultural e Natural.

Destaca-se, pois, que existiram outros acordos internacionais nas últimas quatro décadas que continham linguagem que indicava uma preocupação com o uso sustentável do meio ambiente ou uma preocupação para as gerações futuras, às vezes por referência ao patrimônio comum da humanidade (WEISS , 1993).

A Declaração de Estocolmo sobre o Meio Ambiente Humano de 1972 teve como objetivo assegurar a preservação do meio ambiente em benefício das gerações atuais e futuras, mediante cuidadoso planejamento, constituindo-se como ação inovadora e ousada para os padrões internacionais da época. A Carta Mundial da Natureza de 28 de outubro de 1982, por exemplo, refere-se explicitamente a uma preocupação global pelo patrimônio que deixamos para as gerações futuras:

Consciente do espírito e termos de suas resoluções 35/7 e 36/6, em que convidava solenemente os Estados Membros, no exercício de sua soberania permanente sobre seus recursos naturais, a conduzir suas atividades em reconhecimento da suprema importância da proteção sistemas naturais, mantendo o equilíbrio e a qualidade da natureza e conservando os recursos naturais, no interesse das gerações presentes e futuras (ONU, 1982, s.p.).

O Relatório Bruntland de $1987^{6}$ colaborou grandiosamente para que o Princípio da Responsabilidade Intergeracional tivesse seu avanço institucional no campo internacional, entretanto, até aqui esse princípio não foi claramente enunciado, trazendo ao conhecimento somente uma política de meio ambiente às futuras gerações.

\footnotetext{
${ }^{6}$ Relatório Brundtland é o documento intitulado Nosso Futuro Comum (Our Common Future), publicado em 1987. Neste documento o desenvolvimento sustentável é concebido como: O desenvolvimento que satisfaz as necessidades presentes, sem comprometer a capacidade das gerações fututras de suprir suas prórpias necessidades.
}

CONPEDI LAW REVIEW | QUITO - EQUADOR | v. 4 | n. 2 | p. 1 - 20 | JUL - DEZ | 2018 
No início da década de 1990, a Conferência das Nações Unidas sobre Meio Ambiente e Desenvolvimento (CNUCED) realizada no Brasil marcou o processo de evolução dessa responsabilidade intergeracional, onde foram elaborados documentos relevantes que apontaram um comportamento mais responsável de toda sociedade.

O documento mais importante - para esse estudo - que foi assinado durante a Rio 92 - foi a Declaração do Rio, contendo 27 princípios delineadores da política econômica ambiental moderna (ONU, 2012). Na Declaração do Rio, o princípio norteador da Responsabilidade para as Futuras Gerações está presente no Princípio 3: "O desenvolvimento deve ser promovido de forma a garantir as necessidades das presentes e futuras gerações”. Destarte, a Responsabilidade Intergeracional Ambiental (para as futuras gerações) foi, de forma explícita, consolidada em Tratados, Convenções e Declarações Internacionais, sendo gradualmente introduzida nos diplomas internacionais e nacionais.

No Brasil, a preocupação com as futuras gerações tem sua principal disposição elencada no art. 225 da Constituição Federal de 1988, encontrando-se no "caput" do referido: "Todos têm direito ao meio ambiente ecologicamente equilibrado, bem de uso comum do povo e essencial à sadia qualidade de vida, impondo-se ao Poder Público e à coletividade o dever de defendê-lo e preserva-lo para as presentes e futuras gerações" (grifo nosso) ${ }^{7}$.

Diante do cenário internacional de necessidade de mudanças urgentes, desenvolve-se na América Latina movimento que vem sendo designado como novo constitucionalismo, que se compromete e reflete para uma visão mundial voltada para a harmonia da comunidade humana com a natureza.

Como marco desse novo consitucionalismo, tem-se duas recentes constituições como modelo da tendência, quais sejam: a Constituição do Equador (2008) e a Constituilçao Boliviana (2009), que trazem pardigmas alternativos, pautados em tradições ancestrais, conduzindo a uma discussão de reconhecimento da natureza como sujeito de direitos, rompendo com paradigmas tradicionais. Segundo Acosta (2009), consiste, portanto, em um rompimento com os paradigmas tradicionais construídos pela cultura ocidental, que pautou-se

\footnotetext{
${ }^{7}$ Diante disso, entende-se que o Princípio da Equidade Intergeracional já foi regulamentado, no Brasil, em normas infraconstitucionais, como: Estatuto do Idoso - Lei n. ${ }^{\circ} 10.741$, de $1^{\circ}$ de outubro de 2003 (Estatuto do Idoso) no artigo $3^{\circ}$, inciso IV, quando aborda a viabilização de formas alternativas de participação, de ocupação e de convívio do idoso, proporcionando-lhe sua integração às demais gerações, incentivando a efetivação de programas intergeracionais; Lei da Política Nacional de Educação Ambiental (Lei n. ${ }^{\circ}$ 9.795, de 27 de abril de 1999); Lei da Política Nacional de Resíduos Sólidos (Lei n. ${ }^{\circ}$ 12.305, de 2 de agosto de 2010), ganhando força no Brasil, após a promulgação da CRFB, em 1988.
}

CONPEDI LAW REVIEW | QUITO - EQUADOR | v. 4 | n. 2 | p. 1 - 20 | JUL - DEZ | 2018 


\section{A EQUIDADE INTERGERACIONAL: UMA ANÁLISE DOS DIREITOS DA NATUREZA EM CONSTITUIÇÕES LATINO-AMERICANAS}

numa concepção antropocêntrica de que a titularidade de direitos seria personalíssima da pessoa humana.

\section{A TEORIA DA EQUIDADE INTERGERACIONAL E O DESENVOLVIMENTO SUSTENTÁVEL: HARMONIA DA COMUNIDADE HUMANA COM A NATUREZA}

Primeiramente, é essencial traduzir o significado da palavra natureza, que nas palavras de Gudynas (2009) tem dois sentidos: "por um lado, natureza, como referida às qualidades e propriedades de um objeto ou um ser; e, por outro, natureza para os ambientes que não são artificiais, com certos atributos físicos e biológicos, como espécies de flora e fauna nativas".

Na América Latina, a dinâmica de exploração dos recursos e dos bens da natureza foi trazida e determinada pelo processo de colonização. Com o cenário apresentando mudanças a partir das décadas de 60 e 70, com as conferências das Nações Unidas sobre Meio Ambiente e Desenvolvimento (Estocolmo, 1972, e Rio de Janeiro, 1992) e com os estudos da Ecologia, ocasionando uma maior consciência as alternativas sustentáveis.

Segundo Brown (2002) a sustentabilidade só será possível se olharmos para a Terra e seus recursos, não só como uma oportunidade de investimento, mas como uma confiança, passada por nossos antepassados, para ser apreciada e transmitida aos nossos descendentes para seu uso.

Essa "confiança planetária" nos transmite direitos e responsabilidades. Mais importante ainda, isso implica que as gerações futuras também têm direitos - embora seja certo, esses direitos têm significado somente se os vivos os respeitam e se esse respeito transcende as diferenças entre países, religiões e culturas.

Buscando uma concepção fora da perspectiva econômica ou jurídica, apresenta-se a definição de sustentabilidade trazida por Boff:

Sustentabilidade é toda ação destinada a manter as condições energéticas, informacionais, físico-químicas que sustentam todos os seres, especialmente a Terra viva, a comunidade de vida e a vida humana, visando sua continuidade e ainda atender as necessidades da geração presente e das futuras, de tal forma que o capital natural seja mantido e enriquecido em sua capacidade de regeneração, reprodução e coevolução (BOFF, 2012, p. 107) 
A partir do que foi supracitado, se observa a presença da solidariedade intra e intergeracional. Contudo, é interessante ressaltar como este conceito - ressalta-se, de origem não jurídica ou econômica, parte da compreensão da Terra como um grande organismo vivo. A finalidade é manter não somente a continuidade da vida humana, mas deste grande organismo. Isso se baseia em duas situações: a primeira consiste em afastar a compreensão da natureza como objeto; e a segunda, em definir deveres em relação a ela.

Boff não só inclui expressamente a solidariedade em seu conceito de sustentabilidade como discorre sobre ela em vários pontos da sua obra: "a sustentabilidade obedece a uma racionalidade responsável pelos usos dos recursos escassos" (2012, p. 147). Corresponde a uma partilha equânime dos recursos naturais. O seu fundamento, também para Boff (2012), é ético e equivale ao cuidado no manejo dos bens naturais.

A Carta das Nações Unidas, o Preâmbulo da Declaração Universal dos Direitos Humanos, o Pacto Internacional sobre os Direitos Civis e Políticos, a Convenção sobre Prevenção e Punição do Crime de Genocídio, a Declaração Americana sobre os Direitos e Deveres do Homem, a Declaração sobre a Eliminação da Discriminação contra a Mulher, a Declaração sobre os Direitos da Criança e muitos outros documentos de direitos humanos, revelam uma crença fundamental na dignidade de todos os membros da sociedade humana, e na igualdade de direitos que se estende tanto no tempo como no espaço.

Neste sentido, o Preâmbulo da Declaração Universal dos Direitos Humanos: "Considerando que o reconhecimento da dignidade inerente e dos direitos iguais e inalienáveis de todos os membros da família humana é o fundamento da liberdade, da justiça e da paz no mundo [...]" (OHCHR , 2018, s.p.). A referência a todos os membros da família humana tem uma dimensão temporal, que traz todas as gerações dentro de seu escopo. A referência a direitos iguais e inalienáveis afirma a igualdade básica de tais gerações na família humana.

Brown (1992), por sua vez, afirma que nesta parceria, nenhuma geração sabe de antemão quando será a geração viva, quantos membros terão, ou mesmo quantas gerações haverá em última análise ${ }^{8}$.

\footnotetext{
${ }^{8}$ Brown trata da relação intergeracional exclusivamente sob o ponto de vista humano. Em nenhum momento considera as gerações não humanas como grupo integrante desta relação, ou seja, a Teoria da Equidade Intergeracional formulada por esta autora considera somente as gerações futuras humanas. Mas isso não significa que Weiss adote um posicionamento antropocêntrico, na sua vertente radical, pelo contrário, considera fundamental estabelecer novas bases para a relação ser humano-natureza. No campo jurídico, os autores se dividem quanto ao posicionamento antropocentrista mitigado ou biocentrista do ordenamento jurídico brasileiro CONPEDI LAW REVIEW | QUITO - EQUADOR | v. 4 | n. 2 | p. 1 - 20 | JUL - DEZ | 2018 


\section{A EQUIDADE INTERGERACIONAL: UMA ANÁLISE DOS DIREITOS DA NATUREZA EM CONSTITUIÇÕES LATINO-AMERICANAS}

Isso exige, por conseguinte, que cada geração passe o planeta em condições não pior do que recebê-lo e fornecer acesso equitativo aos seus recursos e benefícios. Cada geração é, portanto, um administrador para o planeta com obrigações de cuidar dele e um beneficiário com direitos para usá-lo.

Existem, pois, dois relacionamentos que devem moldar qualquer teoria da equidade intergeracional no contexto do nosso ambiente natural: nossa relação com outras gerações de nossa própria espécie e nossa relação com o sistema natural do qual fazemos parte.

O segundo relacionamento fundamental é aquele entre diferentes gerações da espécie humana. Todas as gerações estão inerentemente ligadas a outras gerações, passadas e futuras, ao usar o patrimônio comum da terra. A teoria da equidade intergeracional estipula que todas as gerações têm um lugar igual em relação ao sistema natural. Não há base para preferir a geração atual sobre as gerações futuras em seu uso do planeta.

De acordo com Brown (2002), existem três princípios que constituem a base da equidade intergeracional: Primeiro cada geração deve ser necessária para conservar a diversidade da base de recursos naturais e culturais, de modo que não restrinja indevidamente as opções disponíveis para as gerações futuras na resolução de seus problemas e na satisfação de seus próprios valores e também deve ter a mesma diversidade comparável para as gerações anteriores. Este princípio é chamado de "conservação de opções".

Em segundo lugar, cada geração deve ser necessária para manter a qualidade do planeta para que seja transmitida em nenhuma condição pior do que aquela em que foi recebida, e também deve ter direito a uma qualidade planetária comparável à que tem as gerações anteriores. Este é o princípio da "conservação da qualidade". Em terceiro lugar, cada geração deve fornecer aos seus membros direitos de acesso equitativos ao legado das gerações passadas e deve conservar esse acesso para as gerações futuras. Este é o princípio da "conservação do acesso" (BROWN, 2002).

Os princípios propostos reconhecem o direito de cada geração de usar os recursos da Terra para seu próprio benefício, mas restringem as ações da geração atual ao fazê-lo. Dentro dessas restrições, eles não determinam como cada geração deve gerenciar seus recursos.

e, especialmente, da Constituição de 1988. Em posição contrária a de Weiss, estão Sarlet e Fensterseifer (2013), que advogam a favor da abordagem biocentrista no campo jurídico, fundada no reconhecimento do valor da vida. Para os autores o Direito passa agora a tutelar a vida, em todas as suas formas. Eles se posicionam no sentido de se reconhecer uma dignidade animal, que o Direito deve proteger e promover. Outra posição biocêntrica é a de Ayala (2010), que reconhece a dignidade de todas as formas de vida, a qual acarreta a autonomia jurídica da natureza: A dignidade da pessoa humana deve compartilhar do quadro de valores protegidos da mesma proteção que se deve conferir ao valor da dignidade de todas as demais formas de vida.

CONPEDI LAW REVIEW | QUITO - EQUADOR | v. 4 | n. 2 | p. 1 - 20 | JUL - DEZ | 2018 
Eles não exigem que a geração atual preveja as preferências das gerações futuras, o que seria difícil, se não impossível. Em vez disso, eles tentam garantir uma base de recursos naturais razoavelmente segura e flexível para futuras gerações que possam usar para satisfazer seus próprios valores e preferências. Eles geralmente são compartilhados por diferentes tradições culturais e geralmente são aceitáveis para diferentes sistemas econômicos e políticos.

Assim, temos conhecimento atual de que continuidade dos níveis de degradação ambiental levará à exaustão de alguns recursos naturais e a perda da qualidade de outros, impedindo que as próximas gerações tenham liberdade em realizar um projeto próprio de vida e, mais ainda, que tenham uma vida com bem-estar.

Representa, assim, ao descumprimento dos princípios da conservação de opções e da conservação da qualidade ambiental, delineados por Brown (2002) em sua Teoria da Equidade Intergeracional.

Além da liberdade, viola-se tambémo princípio da igualdade, na medida em que cria condições de desigualdade entre as gerações, resultando uma situação de injustiça intergeracional. A igualdade é um comando jurídico que deve ser observado não só em relação ao presente, mas em relação ao futuro.

Desta forma, não considerar os interesses das gerações futuras no presente corresponde a não aplicar a igualdade, como princípio de justiça basilar do Direito, pois favorece um determinado grupo de indivíduos em desfavor de outros.

$\mathrm{O}$ direito ao meio ambiente ecologicamente equilibrado requer proteção a partir de agora, sob pena de os direitos fundamentais das gerações vindouras não serem efetivados.

A solidariedade aparece, portanto, como um instrumento garantista da efetividade dos direitos fundamentais no tempo futuro. Então, o direito fundamental ao meio ambiente ecologicamente equilibrado assume a função instrumental, já que é a partir dele que se realiza e se garante os demais.

Nesta linha, prevê-se a Declaração de Responsabilidades das Gerações Presentes para as Futuras Gerações da UNESCO (1997):

Artigo 3 -Manutenção e perpetuação da humanidade. As presentes gerações devem se esforçar para garantir a manutenção e a perpetuação da 


\section{A EQUIDADE INTERGERACIONAL: UMA ANÁLISE DOS DIREITOS DA NATUREZA EM CONSTITUIÇÕES LATINO-AMERICANAS}

humanidade, com o devido respeito à dignidade da pessoa humana. Por conseguinte, a natureza e a forma de vida humana não devem ser prejudicadas em qualquer aspecto.

Desta feita, os membros da geração atual têm um direito intergeracional de acesso equitativo ao uso e benefício dos recursos do planeta, que deriva da igualdade subjacente e do tratamento igualitário e justo na distribuição dos recursos naturais e culturais entre as gerações

Logo, a conservação da vida não é algo que devemos só a nós mesmos, mas também às novas gerações e o imperativo da responsabilidade nos é incumbido por sermos parte de uma totalidade vivente maior, pois ao sermos a criação mais poderosa da natureza, temos especial responsabilidade - uma ética com a vida.

\section{DESAFIOS PARA UM NOVO CONSTITUCIONALISMO COM INSERÇÃO DA NATUREZA NAS CONSTITUIÇÕES LATINO AMERICANAS}

Em menos de duas décadas um novo oriente de Constitucionalismo tem se desenvolvido na América Latina em decorrência das mudanças políticas, dos novos processos constituintes, das relações entre as populações originárias e o Estado e, especialmente, dos direitos relacionados à titularidade e à proteção da natureza.

O Constitucionalismo Latino-Americano, que a partir do esgotamento dos regimes militares e autoritários dos anos 80, passa a identificar-se com o momento europeu do pósguerra e em um processo de mimetismo, adota padrões teóricos bastante semelhantes àqueles experimentados pelo constitucionalismo europeu.

Nesta perspectiva, as Constituições Latino-Americanas surgidas a partir dos anos 80, fruto do processo de redemocratização na região, reproduzem, em grande medida, compromissos institucionais e respostas jurídicas forjadas a partir de problemas formatados pelo discurso jurídico europeu, reeditando na América Latina uma ideologia constitucional que apresenta dificuldades quanto à realização de suas promessas. As cartas constitucionais necessitavam proteger as liberdades individuais e os direitos sociais. Havia uma grande expectativa de redemocratização e era importante construir textos preocupados com a salvaguarda de direitos e que, ao menos simbolicamente, estivessem comprometidos com ideais democráticos. As linhas mestras desse constitucionalismo pós-ditatorial eram a estabilidade democrática e o fortalecimento dos direitos humanos. 
Em complemento, pode-se afirmar que, o Constitucionalismo Latino-Americano refunda a teoria constitucional abandonando propostas totalizantes e aproximando-se de uma compreensão da realidade caracterizada pela multiplicidade e pelo pluralismo.

Em vistas ao desafio de um novo contitucionalismo, Gudynas (2009) entende que rompe-se com Constitucionalismo tradicional, para a concepção de que "todas as espécies vivas tem a mesma importância e, portanto, merecem ser protegidas (...), independente da versão antropocêntrica".

Almeja-se, consoante inserido na Constituição do Equador, compreender a natureza como ente jurídico, permitindo avançar no enfrentamento da sua implantação legal e sua eficácia junto das instituições legais.

A Constituição Federal de 1988, no Brasil, foi a que primeiro tratou da matéria do meio ambiente, estabelecendo suas diretrizes de regulamentação como um direito social humano, em consonância com a teoria da equidade intergeracional. Assim, a Constituição Brasileira consagrou, no art. 225, a garantia a um meio ambiente ecologicamente equilibrado, impondo "ao poder público e à coletividade o dever de defendê-lo e preservá-lo para as presentes e futuras gerações", como um bem de uso comum da própria sociedade.

Já a Constituição Colombiana em 1991 não trouxe a mesma garantia como a brasileira, dispondo apenas em seu art. 79, que "todas as pessoas têm o direito a gozar de um ambiente sadio".

Nesse contexto, o novo Constitucionalismo Latino-americano passa a ser simbolizado pelas recentes Constituições do Equador (2008) e da Bolívia (2009). Com o destaque Equatoriano por admitir direitos próprios da natureza, direitos ao desenvolvimento do "bem viver" (buen vivir ou sumak kawsay) e o Direito humano à água.

Em seu art. 71, dispõe: “Art. 71. A natureza ou Pacha Mama, onde se reproduz e se realiza a vida, tem direito a que se respeite integralmente a sua existência e a manutenção e regeneração de seus ciclos vitais, estrutura, funções e processos evolutivos".

A Constituição equatoriana desfaz o conceito constitucional clássico do Ocidente pautado nos seres humanos como fonte única de direitos subjetivos e direitos fundamentais para introduzir a natureza como sujeito de direitos, podendo toda pessoa, comunidade, povo, ou nacionalidade poderá exigir à autoridade pública o cumprimento dos direitos da natureza. 


\section{A EQUIDADE INTERGERACIONAL: UMA ANÁLISE DOS DIREITOS DA NATUREZA EM CONSTITUIÇÕES LATINO-AMERICANAS}

Tal constituição também faz referência a bens comuns tais como, água, alimentação, ambiente sadio, cultura, educação, habitat, moradia, saúde, trabalho e segurança, como bens fundamentais à vida e ao bem viver em harmonia com a natureza.

Já a Constituição Boliviana no que se refere aos recursos naturais e o Direito aos bens comuns, admite sua importância, bem como a sua essencial proteção e preservação. Com destaque para a defesa e manejo sustentável dos recursos hídricos, que não podem ser objeto de apropriação privada (art. 374), sendo a água um Direito fundamental para a vida nos marcos da soberania do povo.

Além do inserido na Constituição, na Bolívia tem-se como novo paradigma da tendência constitucionalista latino-americana a publicação da Ley de La Madre Tierra y Desarrollo Integral para Vivir Bien, composta por 58 artigos, que visa criar condições para a harmonia e equilíbrio com a natureza, e traz expressamente em seu artigo quarto a concessão à Madre Tierra da qualificação de sujeito coletivo de interesse público.

O que demonstra forte tendencia a um novo constitucionalismo na América Latina, não estando pautado apenas no homem como centro de direitos e deveres. Em razão dessa nova tendência questiona-se, no Brasil pode um rio pleitear direitos antipoluição na justiça? Pode um cão ter sua guarda compartilhada por um ex-casal?

Sabe-se que essas inclinações podem vir a alterar o estatuto jurídico de animais e da natureza nacionais, apesar de atualmente o Código Civil Brasileiro de 2002 apenas estabelecer duas categorias jurídicas no país: pessoas e coisas.

No dia 23 de março do corrente ano, por exemplo, o Tribunal de Justiça do Estado de São Paulo, através da $7^{\text {a }}$ Câmara de Direito Privado reconheceu que as varas de Família são competentes para solucionar questões relativas à guarda e à visita de animais de estimação.

Considerando que na disputa por um animal de estimação entre duas pessoas após o término de um casamento e de uma união estável há uma semelhança com o conflito de guarda e visitas de uma criança ou de um adolescente, mostra-se possível a aplicação analógica dos artigos 1.583 a 1.590 do Código Civil, ressaltando-se que a guarda e as visitas devem ser estabelecidas no interesse das partes, não do animal, pois o afeto tutelado é o das pessoas.

Além do caso narrado, destaca-se a existência de projetos de lei afetos a matéria: PL 6799/2013: Determina que animais são sujeitos de direitos despersonificados; PL 3670/2015: Determina que animais não sejam considerados coisas, mas bens móveis para efeitos legais. 
Não só, o Brasil possui um caso representativo quanto aos direitos da natureza, quando em 5/11/2017, o Rio Doce, através da ONG Associação Pachamama, entrou com ação na Justiça Federal de Minas para ser reconhecido como sujeito de direitos, à vida, e que seja feito um plano de prevenção a desastres para proteger toda a população da bacia do rio (NOVAES, 2018).

Assim, tem-se que os objetivos estão postos e que o Constitucionalismo pluralista que se instaurou na América Latina a partir de mudanças políticas e novos processos sociais apresentados, com influência das tendências internacionais e conscientização em prol do meio ambiente e da equidade intergeracional, é uma realidade, tendo como destaque impulsionador as Constituições do Equador (2008) e da Bolívia (2009), inspirando e legitimando novos paradigmas dos bens comuns culturais, em prol da natureza e dos animais.

\section{CONSIDERAÇÕES FINAIS}

Diante de tudo que foi exposto, pode-se afirmar que este artigo sugere uma estrutura normativa em que, se for adotada e internalizada por nossas instituições políticas e sociais, pode assegurar que as futuras gerações herdem uma parcela justa de herança ambiental global, pois a espécie humana apenas detém os recursos naturais e culturais do planeta em confiança para todas as outras gerações.

Essa confiança planetária, impõe a cada geração a preservação da diversidade, da base de recursos para que as gerações futuras recebeam o planeta em condições ainda melhores que a geração atual.

À vista da teoria da equidade intergeracional, surge uma tendência latino-americana no Século XXI, rompendo com a influência antropocênctrica ocidental tradicional, para reconhecer direitos à natureza e aos animais nas Constituições.

O denominado como novo Constitucionalismo Latino-americano tem como marco emblemático as recentes Constituições do Equador (2008) e da Bolívia (2009). Com o destaque Equatoriano por admitir direitos próprios da natureza, direitos ao desenvolvimento do "bem viver" (buen vivir ou sumak kawsay) e o Direito humano à água.

No Brasil, a Constituição Federal de 1988, foi a que primeiro tratou da matéria do meio ambiente, estabelecendo suas diretrizes de regulamentação como um direito social humano, em consonância com a teoria da equidade intergeracional. 


\section{A EQUIDADE INTERGERACIONAL: UMA ANÁLISE DOS DIREITOS DA NATUREZA EM CONSTITUIÇÕES LATINO-AMERICANAS}

Assim, a Constituição Brasileira consagrou, no Art. 225, a garantia a um meio ambiente ecologicamente equilibrado, impondo "ao poder público e à coletividade o dever de defendê-lo e preservá-lo para as presentes e futuras gerações", como um bem de uso comum da própria sociedade. Apesar de não reconhecer, em seu bojo, a fauna e a flora, como sujeitos de direito.

No entanto, destaca-se recente julgado, pelo Tribunal de Justiça do Estado de São Paulo, em que se reconheceu que as varas de Família são competentes para solucionar questões relativas à guarda e à visita de animais de estimação.

Além destemomento supracitado, importante e precursora ação foi protocolada em 2017, em que o Rio Doce, através da ONG Associação Pachamama, entrou com ação na Justiça Federal de Minas para ser reconhecido como sujeito de direitos, à vida, e que seja feito um plano de prevenção a desastres para proteger toda a população da bacia do rio.

Diante dos exemplos nacionais mencionados, consegue-se inferir que a tendência latino-americana (à exemplo do Equador e da Bolívia) de romper para com paradigmas antropocêntricos ocidentais, com a finalidade de reconhecer direitos a natureza como sujeitos de direito, está cada vez mais próximo do Brasil, que em sua Constituição de 1988 já reconhece a teoria da equidade intergeracional como anseio em nome das presentes e futuras gerações.

Por fim, destaca-se que o novo Constitucionalismo que se instaurou na América Latina a partir de mudanças políticas e novos processos sociais, pautados em conferências internacionais e uma conscientização em prol do meio ambiente para equidade intergeracional, se configura em uma realidade que inspira e tenta legitimar novos paradigmas dos bens comuns culturais, em prol da natureza e dos animais.

Dessa forma, infere-se que o Constitucionalismo Latino-Americano tem demonstrado um esforço em possibilitar a democracia a partir do empoderamento de parcela da população historicamente marginalizada, como índios, mulheres, campesinos, negros, em países com um constitucionalismo excludente e com histórico de golpes de Estado.

Esta pesquisa foi realizada de maneira inicial, com jurisprudência brasileira do corrente ano, estando o tema em desenvolvimento e debate no país e na América Latina, portanto, podendo contribuir para novas discussões e debates acadêmicos, principalmente ao que concerne a futuros dados e decisões judiciais, reconhecendo a natureza como sujeito de direito, para uma equidade intergeracional. 


\section{REFERÊNCIAS}

ACOSTA, Alberto. Los grandes cambios requieren de esfuerzos audaces. A manera de prólogo”. In: ACOSTA, Alberto; MARTíNEZ, Esperanza (Comps.) Derechos de la Naturaleza. El Futuro es Ahora. Quito: Abya Yala, 2009.

AYALA, Patrick de Araújo. A proteção jurídica das futuras gerações na sociedade de risco global: o Direito ao Futuro na Ordem Constitucional Brasileira. In: LEITE, José Rubens Morato; FERREIRA, Heline Sivini; BORATTI, Larissa Verri. Estado de Direito Ambiental: tendências. 2. ed. Rio de Janeiro: Forense Universitária,2010.

BOFF, Leonardo. Sustentabilidade: o que é - o que não é. Petrópolis: Vozes, 2012.

BOLSON. Simone Hegele. A dimensão filosófico-jurídica da equidade intergeracional: reflexões sobre as obras de Hans Jonas e Edith Brown Weiss. In: Direitos Fundamentais \& Justiça - Ano 6, No 19, p.210-236, Abr/Jun. 2012.

BRASIL. Constituição da República Federativa do Brasil. 1988. Brasília: Senado Federal, 1988.

Decreto $n^{\circ} 7030$, de 14 de dezembro de 2009. Convenção de Viena sobre o Direito dos Tratados. Disponível em: <http://www.planalto.gov.br/ccivil_03/_ato2007-2010 /2009/decreto/d7030.htm>. Acesso em: 5 maio 2018.

CARVALHO, Edson Ferreira de. Meio ambiente \& direitos humanos. Curitiba: Juruá Editora, 2006.

CONSULTOR JURÍDICO. Acórdão da decisão 2052114-.2018.8.26.0000. Disponível em: $\langle$ https://www.conjur.com.br/dl/vara-familia-julga-guarda-compartilhada.pdf $>$. Acesso em: 02 Jun. 2018.

GUDYNAS, Eduardo. El Mandato Ecológico. Derechos de La Naturaleza y Políticas Ambientales en La Nueva Constitución. Quito: Abya Yala, 2009.

INSTITUT DE DROIT INTERNATIONAL. Annuaire. Tome 56. Session de Wiesbaden, 1975. Justitia et Pace. Editions S. Karger AS. Bale, 1975. Le problème intertemporel en droit international public/The Intertemporal Problem in Public International Law. Disponível em:〈http://www.idi-iil.org/app/uploads/2017/05/4025-56-ocr.pdf>. Acesso em: 24 abr. 2018.

JONAS, Hans. O princípio da responsabilidade: ensaio de uma ética para a civilização tecnológica. Tradução Marijane Lisboa e Luiz Barros Montez. Rio de Janeiro: Contraponto: PUC Rio, 2006.

KIS, Alexandre. Os direitos e interesses das gerações futuras e o princípio da precaução. In: VARELLA, Marcelo Dias; PLATIAU, Ana Flávia Barros (Organizadores e co-autores).

Princípio da Precaução. Belo Horizonte: Del Rey e ESMPU - Escola Superior do Ministério Público da União, 2004.

CONPEDI LAW REVIEW | QUITO - EQUADOR | v. 4 | n. 2 | p. 1 - 20 | JUL - DEZ | 2018 
LEITE, José Rubens Morato; AYALA, Patrick de Araújo. A transdisciplinariedade do Direito Ambiental e sua equidade intergeracional. Revista de Direito Ambiental. São Paulo, ano 6, $\mathrm{n}^{\mathrm{o}} 22,2001$, pp. 63-80.

LIMA, Cristina R. Programas intergeracionais: um estudo sobre as atividades que aproximam as diversas gerações. Campinas: Alínea, 2008.

MACWHINNEY. The Time Dimension in International Law: Historical Relativism and Intertemporal Law. In: Essays in International Law in Honour of Judge Manfred Lachs, 1979.

NOVAES, Lafayette. Excelentíssimo juiz federal da seção judiciária de minas gerais Belo Horizonte/MG. Disponível em:

<https://docs.wixstatic.com/ugd/da3e7c_8a0e636930d54e848e208a395d6e917c.pdf>. Acesso em 04 de Junho de 2018.

OHCHR. Declaração Universal dos Direitos Humanos. Disponível em:

<http://www.ohchr.org/EN/UDHR/Documents/UDHR_Translations/por.pdf>. Acesso em 16 de março de 2018.

ONU - ORGANIZAÇÕES DAS NAÇÕES UNIDAS. Declaração de Estocolmo sobre Meio Ambiente Humano. Disponível em:〈www.mma.gov.br/estruturas/agenda21/_arquivos/estoc olmo.doc>. Acesso em: 10 abr. 2018.

Declaração do Rio sobre Meio Ambiente e Desenvolvimento. Disponível em:<http://www.onu.org.br/rio20/img/2012/01/rio92.pdf >. Acesso em: 10 maio 2018.

Carta Mundial da Natureza. Disponível

em: $<$ http://www.dhcii.eu/0_content/investigao/files_CRDTLA/convencoes_tratados_etc/carta _mundial_da_natureza_de_28_de_outubro_de_1982.pdf $>$. Acesso em: 18 mar. 2018.

RAWLS, John. Uma teoria da justiça. Tradução de Jussara Simões. 3. ed. São Paulo: Martins Fontes, 2008.

SARLET, Ingo Wolfgang; FENSTERSEIFER, Tiago. Direito Constitucional Ambiental: Constituição, Direitos Fundamentais e Proteção do Ambiente. 3. ed. rev., atual. e ampl. São Paulo: Revista dos Tribunais, 2013.

TRINDADE, Cançado, A. A. The Application of the Rule of Exhaustion of Local Remedies in International Law. 1983.

UNESCO. Declaration on the Responsabilities of the Present Generations Towards Future Generations. Disponível em: 〈http://www.unesco.org/cpp/uk/declarations/generatio ns.pdf >. Acesso em: 11 maio 2018. 
UNITED NATIONS. Report of the united nations conference - on the human environment. Stockholm, 546, June 1972. Disponível em:

<http://www.un.org/ga/search/view_doc.asp?symbol=A/CONF.48/14/REV.1>. Acesso em: 04 abr. 2018.

WEISS, E. B. Our rights and obligations to future generation for the environment. Revista Instituto Interamericano de Derechos Humanos. São José (Costa Rica), v. 13, p.21-33, jan./jun. 1991. Disponível em: <http://www.juridicas.unam.mx/publica/librev/ rev/iidh/cont /13/dtr/dtr2.pdf>. Acesso em: 11 maio 2018.

Intergenerational equity: a legal framework for global environmental change. 1993. Disponível em: <http://scholar.google.com.br/scholar?q=Intergenerational+equity:+ a+legal+framework+for+global+environmental+change \&hl=pt-BR\&as_sdt=0\&as_vis $=1 \& o i$ =scholart> Acesso em: 4 maio 2018 .

The Planetary Trust: Conservation and Intergenerational Equity. Revista Ecoly Law Quarterly. 1984. pp. 540-563.

WARREN, Lynda. Intergenerational equity. Committe on Radioactive Waste ManagementCORWM. 2004. Disponível em: <www.corwm.org.uk/PDF/673\%20-\%Intergener ational\%20Equity.pdf.>. Acesso em: 12 jun. 2016. 